\title{
Desenvolvimento de um Ambiente de Robótica Educacional para o Ensino de Programação com Hardware Livre
}

\author{
Rafael G. Cerci ${ }^{1}$, Julio C. S. Ferreira ${ }^{1}$, Helio H. L. C. Monte-Alto ${ }^{1}$ \\ ${ }^{1}$ Universidade Federal do Paraná - Palotina - PR - Brasil \\ \{rafael.cerci, juliosilva, heliohenrique\}@ufpr.br
}

\begin{abstract}
The usage of technologies, such as educational robotics in the classroom, makes the teaching and learning process more playful, contributing to arouse greater interest in students. The tool proposed in this work is a robot which draws in a slate, with eased manipulation in the classroom and low assembly cost, since it is based on free hardware and software. It is intended, from this prototype, to develop an integrated software and hardware environment as a version of a Logo-programming environment, in which students provide commands similar to the Logo programming language to make the robot draw using mathematical concepts, thus contributing to the computational and mathematical thinking development of the students. This work presents the assembly of the hardware and the preliminary tests already performed, as well as the software architecture of the designed application and the next steps.
\end{abstract}

Resumo. O uso de tecnologias, tais como a robótica educacional em sala de aula, torna o processo de ensino e aprendizagem mais lúdico, contribuindo para despertar um maior interesse nos estudantes. A ferramenta abordada neste trabalho é um robô que desenha em uma lousa, de fácil manipulação em sala de aula e de baixo custo para a sua construção, por ser baseado em hardware e software livres. Pretende-se, a partir desse protótipo, desenvolver um ambiente integrado de software e hardware como uma versão de um ambiente de programação Logo, no qual os alunos fornecerão comandos similares aos de uma linguagem de programação Logo para que o robô desenhe utilizando conceitos matemáticos, contribuindo para com o desenvolvimento do pensamento computacional e matemático dos alunos. Este trabalho apresenta a montagem do hardware e os testes preliminares que já foram realizados, assim como a arquitetura de software da aplicação projetada e os próximos passos.

\section{Introdução}

Educar é uma tarefa colaborativa entre professores e alunos. O aprendizado, se não acontecer de forma natural e atrativa para o aluno, torna-se árduo para o aluno e cansativo para o professor. O ensino tem sido feito, ao longo de muitos anos, por meio de símbolos, signos e outros instrumentos que estabelecem a relação entre os alunos e os objetos do conhecimento. [Benitti et al. 2009] coloca a questão de forma muito interessante:

"Atualmente, os estudantes do ensino básico estão imersos em um ambiente em que a tecnologia é facilmente percebida: carros, celulares e computadores são exemplos que todos conhecem e muitos utilizam, no entanto, poucos entendem. Estes mesmos estudantes passam boa parte de 
VI Congresso Brasileiro de Informática na Educação (CBIE 2017)

Anais do XXIII Workshop de Informática na Escola (WIE 2017)

seu tempo na escola estudando conteúdos de matemática e física e, paradoxalmente, os conceitos que lhes são apresentados parecem distantes."

Pensando em outros meios de apoiar e instigar a aprendizagem, este estudo visa à procura de meios alternativos de ensino com a finalidade de melhorar o desempenho dos alunos e estimular um maior interesse pelas disciplinas de Matemática e Computação.

Atualmente, existem várias ferramentas que podem ser utilizadas no ambiente de ensino por meio da robótica. A plataforma Arduino ${ }^{1}$ é um exemplo de hardware livre, de baixo custo e de fácil manuseio. Com a utilização de um Arduino é possível desenvolver projetos que ajudem a trabalhar em sala de aula com diversos conceitos de Matemática básica, tais como números, equações de primeiro e segundo grau, gráficos, geometria, porcentagem, frações, o plano cartesiano, entre outros conteúdos.

O presente trabalho apresenta o desenvolvimento de um robô desenhador de lousa baseado no projeto de robô artístico de código aberto Makelangelo. O Makelangelo consiste em um robô que desenha pôsteres e murais, cujo objetivo é sua utilização para o ensino de conceitos de programação, física, trigonometria e eletrônica de forma divertida e orientada a objetivos [Makelangelo 2017]. Os autores também sustentam que os objetivos educacionais do robô seguem o conceito interdisciplinar chamado STEAM - Ciência, Tecnologia, Engenharia, Artes e Matemática (do Inglês, Science, Technology, Engineering, Arts and Math). De acordo com os desenvolvedores do projeto [Makelangelo 2017]:

"Pode ser difícil tornar o ensino de STEAM relevante para as crianças. Um Makelangelo não executa sem trigonometria, pi ou álgebra básica. É fácil usar o robô para tornar aulas de STEAM relevantes e oportunas. Temos certeza de que o Makelangelo dará aos alunos a experiência que precisam para serem bem-sucedidos em assuntos mais difíceis mais tarde."

Além de utilizar as ideias educacionais nativas do Makelangelo, planeja-se a implementação de um ambiente Logo utilizando o robô. Logo é uma linguagem de programação educacional criada por Seymour Papert [Papert 1972]. Esta linguagem, disponível em diversas versões, consiste em um ponteiro, comumente chamada de "tartaruga", para o qual é possível programar comandos para que se mova num espaço bidimensional. Por onde a "tartaruga" passa neste espaço, ela desenha uma linha, como se estivesse segurando uma caneta ou lápis. Assim, as crianças aprendem a programar desenhando figuras geométricas e até mesmo desenhos mais complexos. A Figura 1 mostra um exemplo de um software Logo no qual são inseridos comandos para desenhar um quadrado, de forma muito simples e com apenas uma linha de código.

Portanto, a ideia deste trabalho é criar uma linguagem que interaja com o robô desenhador de lousa de modo similar à linguagem Logo, instigando e permitindo o aprendizado tanto de Matemática quanto de programação de computadores de forma lúdica. Pretende-se, assim, colocar à disposição do professor uma ferramenta que torne o ensino de Matemática mais significativo para os alunos. Colocando em prática alguns conceitos matemáticos, o aluno poderá visualizar o emprego prático do conteúdo em questão, despertando, assim, um maior interesse pela busca do conhecimento matemático.

A próxima seção apresenta a metologia utilizada neste trabalho. A Seção 3 apresenta brevemente um relato sobre o desenvolvimento do protótipo do robô. A Seção 4

\footnotetext{
${ }^{1}$ https://www.arduino.cc
} 
VI Congresso Brasileiro de Informática na Educação (CBIE 2017)

Anais do XXIII Workshop de Informática na Escola (WIE 2017)

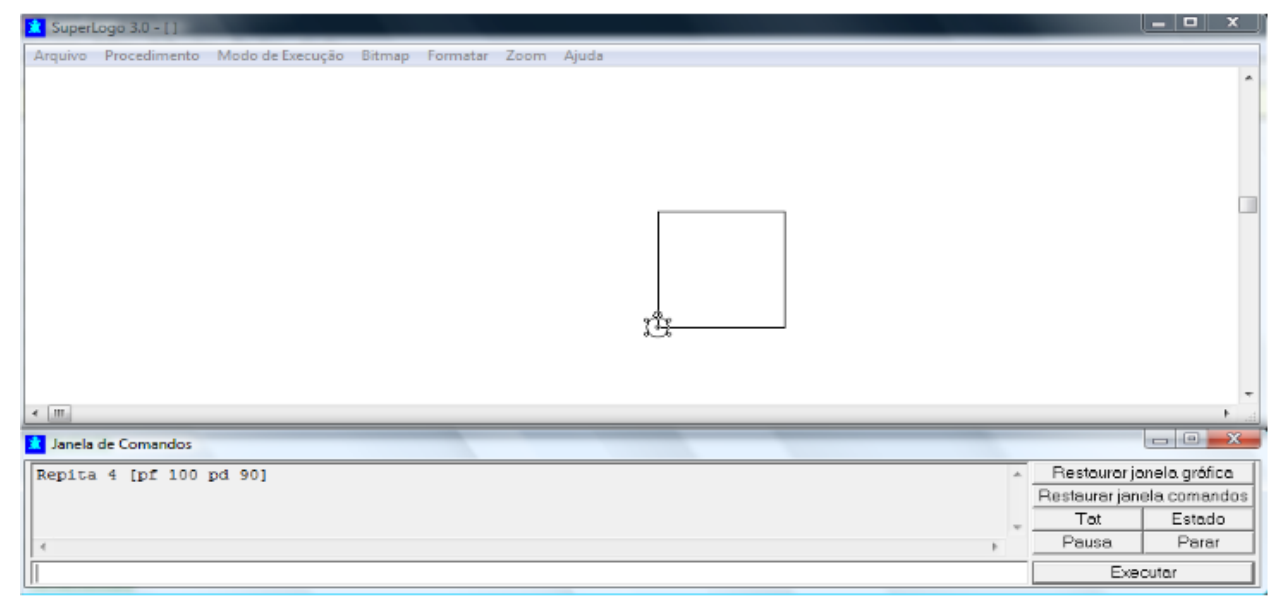

Figura 1. Imagem do software SuperLogo, uma das muitas implementação da linguagem Logo.

apresenta uma breve descrição da arquitetura pretendida para o ambiente Logo. Por fim, são apresentadas considerações finais e trabalhos futuros.

\section{Metodologia}

O desenvolvimento deste trabalho foi dividido nas seguintes etapas: (I) pesquisa sobre projetos similares ao pretendido; (II) montagem do hardware do robô utilizando a plataforma Arduino; (III) utilização de software fornecido pelos projetos similares encontrados para realização dos testes do hardware; (IV) planejamento e projeto da arquitetura do software do ambiente Logo; (V) implementação da firmware (programa gravado diretamente no hardware) para o Arduino; (VI) implementação da linguagem Logo; e (VII) implementação da interface com o usuário (PC, Android, etc.).

Tendo encontrado o Makelangelo como uma solução de código aberto (software livre), foi iniciada a montagem do robô. O pacote de software fornecido pelo Makelangelo foi utilizado para testes. Uma vez que o hardware está pronto e funcional, o próximo passo será o desenvolvimento do ambiente de software que dará apoio à programação no estilo da linguagem Logo de modo integrado à lousa. $\mathrm{O}$ primeiro passo em direção a isso é a concepção da arquitetura do sistema, apresentada na Seção 4.

\section{Desenvolvimento do Hardware e Testes}

Primeiramente foi feito um planejamento para a montagem do hardware, assim como o estudo do software e da plataforma de desenvolvimento do Makelangelo. Para alguns dos itens usados para confeccionar o robô foram utilizados materiais reciclados. A seguir são listados os itens básicos utilizados para a confecção do robô: dois motores de passo Nema 17, duas polias GT2, 3 metros de correia aberta $5 \mathrm{~mm}$, um servo motor, uma fonte $5 \mathrm{~V} 2 \mathrm{~A}$, um quadro branco de $60 \times 90 \mathrm{~cm}$, parafusos M4 (pode ser utilizado fita dupla face), presilhas plásticas, duas garrafas (pode ser de água mineral $500 \mathrm{ml}$ ), fita isolante, duas pilhas (ou algo similar para usar como contra peso), uma peça suporte para a caneta (pode ser impressa em uma impressora 3D). Alguns itens podem ser trocados por materiais alternativos. A Figura 2 apresenta uma foto do hardware montado. 
Conclui-se que o hardware resultante, além de uma excelente ferramenta de apoio ao ensino, é de montagem relativamente fácil e que pode ser realizada pelos próprios alunos em projetos relacionados ao movimento maker com Arduino, tais como hackerspaces e iniciativas similares.

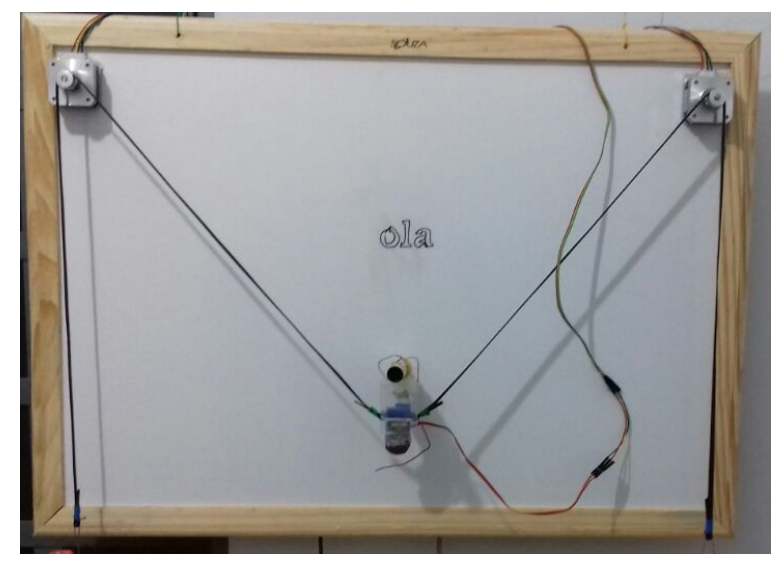

Figura 2. Robô desenhador de lousa montado.

\section{Arquitetura do Ambiente de Programação Logo}

A Figura 3 apresenta uma visão geral da arquitetura de software do ambiente de programação. A arquitetura é dividida em 3 (três) camadas: (1) camada de firmware; (2) camada de interpretador da linguagem; e (3) camada de interface com o usuário. Cada uma das camadas deverá ter interfaces bem definidas com a(s) camada(s) subjacente(s). A camada de firmware deve implementar uma API (Application Programming Interface) que define os comandos básicos a nível de hardware e os implemente na linguagem de programação da plataforma Arduino. A camada de interpretador deve implementar os comandos de alto nível da linguagem Logo a ser desenvolvida (e.g., os comandos parafrente $(x)$, que permite fazer a "tartaruga" andar x passos para frente, e o comando girar (a), que permite fazer a "tartaruga" girar a graus). Enfim, a camada de interface com o usuário deverá implementar o modo como o usuário criará os comandos que a "tartaruga", representada pela caneta na lousa, deverá executar. A ideia é implementar uma linguagem de blocos, similar à linguagem Scratch [Maloney et al. 2010], a fim de tornar a programação mais intuitiva e divertida para os alunos. Também pretende-se criar diferentes versões da interface com o usuário, tais como as que executarão em PCs, smartphones e tablets, permitindo, assim, uma maior facilidade de acesso, principalmente para uso em sala de aula.

\section{Considerações Finais e Trabalhos Futuros}

Este projeto é um primeiro passo no sentido de criar uma ferramenta integrada de software e hardware que utiliza o conceito de robótica educacional no ensino de programação, em especial na Educação Básica. Uma vez que trata-se de um robô que desenha em uma lousa, um objeto muito familiar aos alunos, cremos que será possível realizar atividades lúdicas e motivadoras que despertem o interesse dos alunos e os instiguem à construção do conhecimento, conforme o propósito original da linguagem Logo. Além disso, o robô baseado no Makelangelo é uma excelente ideia a ser desenvolvida em projetos do movimento maker, tais como hackerspaces. 
VI Congresso Brasileiro de Informática na Educação (CBIE 2017)

Anais do XXIII Workshop de Informática na Escola (WIE 2017)

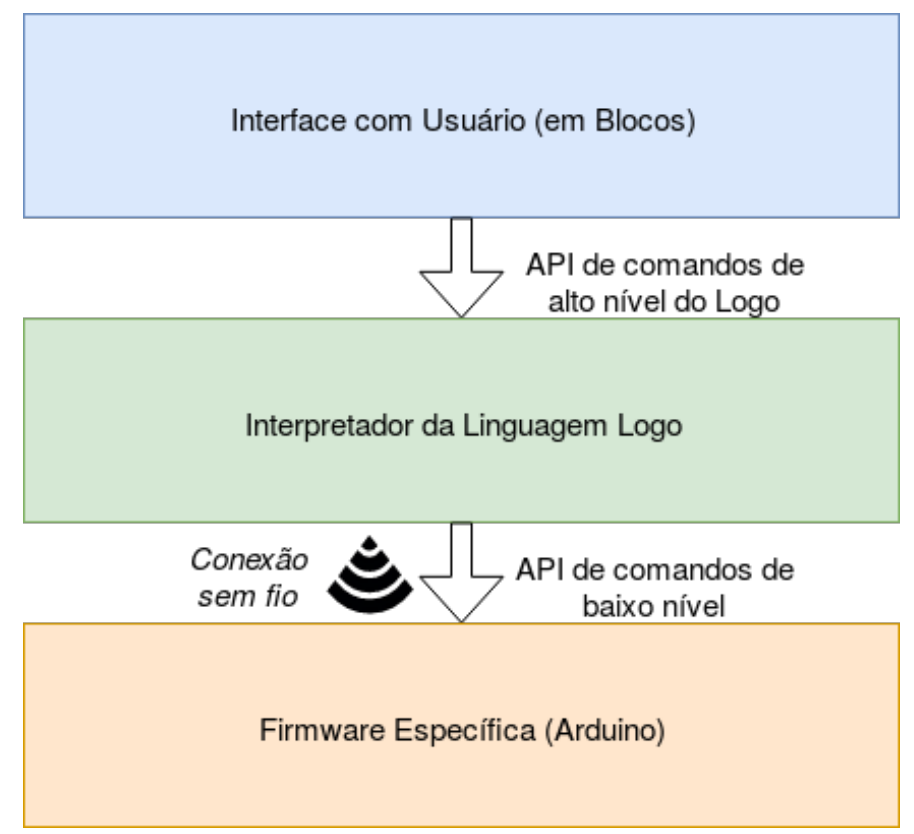

Figura 3. Representação da arquitetura do ambiente de programação

Uma vez que já realizamos a montagem inicial do hardware e os testes, o próximo passo é desenvolver a API e firmware que controlará o robô a partir da placa Arduino. A ideia é desenvolver um conjunto de procedimentos básicos na linguagem de programação do Arduino para permitir os movimentos simulados da "tartaruga". A seguir, após todos os testes serem feitos com essa firmware, passaremos ao desenvolvimento das camadas superiores: os comandos e API do interpretador, que deverão invocar os comandos definidos na firmware por meio de algum tipo de conexão sem fio (tal como Bluetooth ou $W i-F i$ ). Por fim, será desenvolvido a parte gráfica, no qual serão implementados os blocos de encaixar a partir dos quais serão invocados os comandos da linguagem.

Pretende-se, após ao término da implementação e testes da arquitetura definida, expandir a mesma ideia para outros dispositivos robóticos, tais como carrinhos e outros robôs móveis.

\section{Referências}

Benitti, F. B. V., Vahldick, A., Urban, D. L., Krueger, M. L., and Halma, A. (2009). Experimentação com robótica educativa no ensino médio: ambiente, atividades e resultados. In Anais do Workshop de Informática na Escola, volume 1, pages 1811-1820.

Makelangelo (2017). The makelangelo art robot: What is a makelangelo. Disponível em http://www.makelangelo.com/. Último acesso em 24 de junho de 2017.

Maloney, J., Resnick, M., Rusk, N., Silverman, B., and Eastmond, E. (2010). The scratch programming language and environment. Trans. Comput. Educ., 10(4):16:1-16:15.

Papert, S. (1972). Teaching children to be mathematicians versus teaching about mathematics. International Journal of Mathematical Education in Science and Technology, 3(3):249-262. 